\title{
Pursuing a sense of the emergent through craft practices in architectural design
}

\author{
Michael Davis
}

\begin{abstract}
This paper focuses on 'craft' (as an aggregation of iterative actions) both as an aspect of architectural design practices, and in relation to the paradigm of emergence. The aim is to reconsider the idea of emergence in relation to everyday design practices, and to examine how the craft aspect of architectural design practices might become present in architectural outcomes.
\end{abstract}

The paper explores a notion of emergent craft as it pertains to architectural design through a comparison between two of the author's projects: the first while studying at the Architectural Association's Design Research Laboratory (AADRL), London, in 2002 (Kinetetras - a prototype for a flexible, programmable space frame exhibited at the Latent Utopias exhibition in Graz, Austria); and, the second, a small house produced some ten years later at Lang's Beach in New Zealand.

Through a discussion of the design processes of the two projects, craft is explored in terms of Steven Johnson's notion of emergence, and in relation to Donald Schön's notion of reflection-in-action, and further in relation to Peter Downton's notion of knowing-through-making. The paper articulates a difference between knowing-through-drawing and knowing-throughmodelling as emergent forms of knowledge. Working through these terms the paper identifies two issues: The first is that knowing-through-drawing and knowing-through-crafting models are complementary ways of knowing-through-making; the second is that they operate in tension. What emerges in relation to that tension is a quality of approach to design which is termed 'craftiness'. It is characteristically collage-like and presents in the architectural outcome as its defining quality.

The paper concludes with a summary comparison between the two projects, and articulates the Lang's project as a re-grounding and expansion of research into emergent complexity in the context of an everyday design practice.

\section{Introduction}

The idea of craft in relation to the practice of architecture is problematic, for while the craft of the artisan concerns the making of an artefact, the craft of the architect concerns the making of representations of an artefact to be made by others. The craft endeavour of the architect, then, would seem to be suspended in the architectural representation - the beautifully made drawing, render or model. Or would it? 
This paper focuses on 'craft' (as an aggregation of iterative actions) both as an aspect of architectural design practices, and in relation to the paradigm of emergence. The aim is to reconsider the idea of emergence in relation to everyday design practices, and to examine how the craft aspect of architectural design practices might become present in architectural outcomes. While craft might be identified through its bearing evidence of the hand, might it also be identified in the work as an emergent quality?

Craft will be explored in terms of Steven Johnson's notion of emergence, and in relation to Donald Schön's notion of reflection-in-action and, further, in relation to Peter Downton's notion of knowing-through-making. This exploration takes place through a discussion of two of my projects: the first undertaken while studying at the Architectural Association's Design Research Laboratory (AADRL), London, in 2002 (a prototype for a flexible, programmable space frame exhibited at the Latent Utopias exhibition in Graz, Austria); and, the second being a small house produced some ten years later in New Zealand.

The text is punctuated with notation taken either directly from my sketchbooks or made in relation to notation in my sketchbooks. The intention is to retain immediacy between the workings of the project and the reflection which draws out the issues encountered in the design process.

\section{Craft}

To the Arts and Crafts movement of the nineteenth century, the idea and work of craft stood in opposition to mass-production and the mechanisation of human labour that was brought about by the industrial revolution (Metcalf 2002). Oxford Dictionaries online provides a less politicised, more general idea of craft that reaches back to the pre-industrial and connects forward to the present: craft is 'an activity involving skill in making things by hand' (2012). In The Craftsman (2008), Richard Sennett writes about craft across a range of creative practices. In contrast with the dictionary definition, Sennett does not position the 'hand' at the centre of craft. In the prologue he presents an initial definition of craftsmanship as 'the skill of making things well' and the motivation of the craftsman as '.. an enduring, basic human impulse, the desire to do a job well for its own sake' (2008: 8-9). If this is so, how might we think about craftsmanship and its role if it is understood as a particular kind of behaviour operating across and within the architectural design process?

For me the issue is not industrialisation, rather it is the presumed to be intellectual, cognitive or 'hands-off' role of the professional architect compared to the craftsman (whether industrial or pre-industrial). What this paper offers to this issue of craft + design enquiry is a perspective on architectural design as a practice of making (objects, buildings, environments ... cities). Architectural design here might be demonstrated to engage the designer materially, physically, 
cerebrally, emotionally, socially and environmentally. Through this engagement particular kinds of embodied knowledge might be seen to emerge. It is through the lens of the paradigm of emergence that this perspective is constructed.

\section{The paradigm of emergence - geometry and craft}

Johnson's paradigm of emergence is an idea about how things happen in the world. It explains the coming-into-being of things not as the result of a single action, or central controlling force, but as the result of an aggregation of multiple, small actions related by simple rules. He writes in relation to selforganising systems:

They are bottom-up systems, not top-down. They get their smarts from below. In a more technical language, they are complex adaptive systems that display emergent behavior. In these systems, agents residing on one scale start producing behavior that lies one scale above them: ants create colonies; urbanites create neighborhoods; simple pattern-recognition software learns how to recommend new books. The movement from lowlevel rules to higher sophistication is what we call emergence'. (2002: 18)

The formal language of emergence in architecture, as expounded by figures such as Michael Hensel, Achim Menges \& Michael Weinstock, might be characterised similarly, where a single geometric cell is extensively repeated and varied in relation to the previous repetition (Figure 1). The aggregate of these repeated geometries, simple geometric units in simple, part-to-part relationships, is extrapolated into a material system that is often described as presenting an 'emergent complexity'.

I found cause to question this.
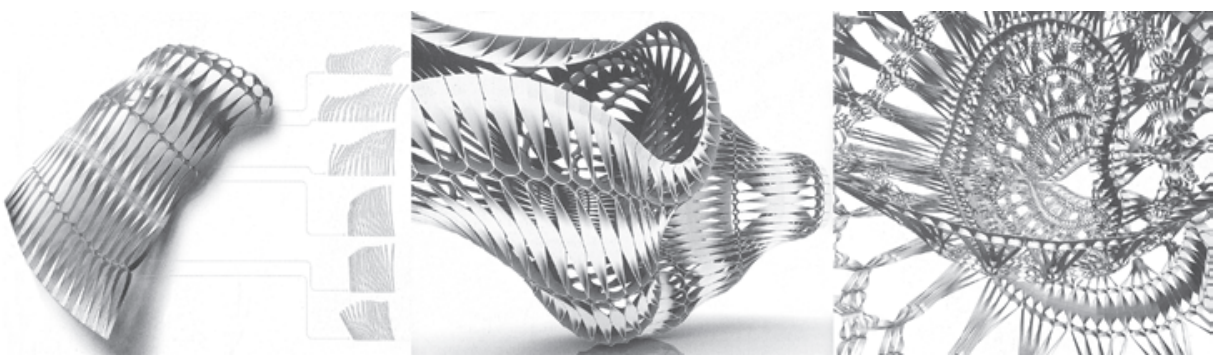

Figure 1. Achim Menges, paperstrip morphologies, 2004-2005.

Source: M. Hensel, A. Menges, A. et al. 2006, Morpho-ecologies, London, Architectural Association

My research leading to a Master of Architecture degree at the AADRL contributed to this agenda. The educational environment was intense - many people in a small studio working iteratively and collaboratively to develop and test design propositions. Concerns about the work nagged at me, but any musings had to be suspended for the need to just focus on producing work. That included suspending questions as to how any of the work might be of benefit to me on 
my return to the South Pacific. It also included suspending doubt as to the relationship of the formal outcomes of the AADRL to the actual phenomena of emergence - I suspected that we were formally illustrating an idea of emergence rather than exploring the notion.

In August 2002, having been at the AADRL for three terms - working intensively on the development of a flexible, tetrahedral programmable space frame - I was charged with making a full-scale prototype of the system for the Latent Utopias exhibition in Graz, Austria (Figure 2). Kinetetras (as it was called) consisted of six steel tetrahedrons, pivot jointed together, which operated across their upper apexes by pneumatic actuators. Attached to the underside of this structure was a surface consisting of 648 vacuum-formed plastic bubbles.

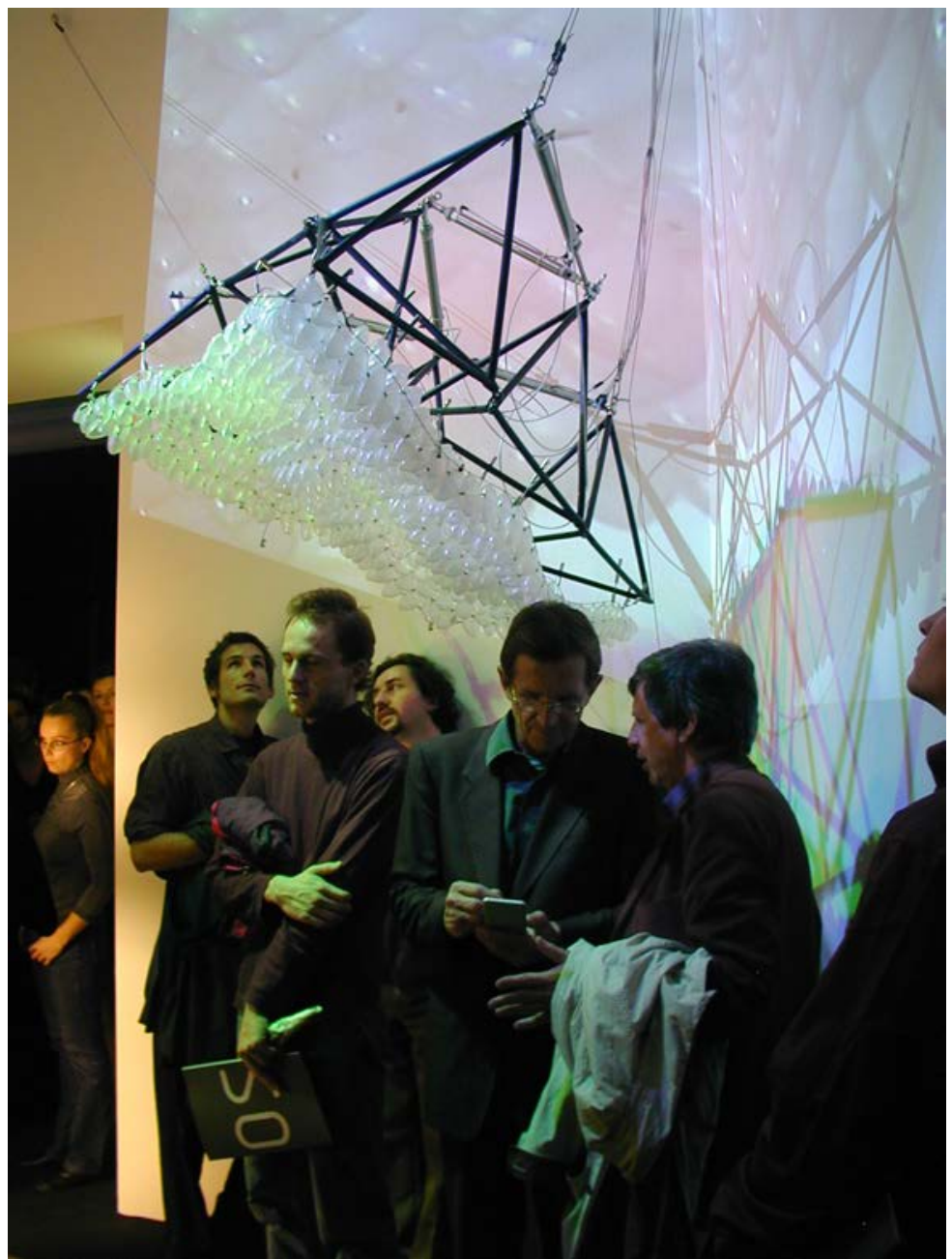

Figure 2. 'd_rive' (Michael Davis, Steven Hatzellis, Anat Stern), Kinetetras, exhibited Latent Utopias, Graz, Austria, 2002.

Photography: Steven Hatzellis 
The Kinetetras prototype was to be extrapolated into an urban proposition for the Barbican. We had poured time and energy into this larger project, but still had no idea what it was, of how the system might be extended to define it, of what the system would become at a body, building, city scale. And I (again) had to suspend my worry that we had only one term to run before this unseen project was to be completed (Figure 3).

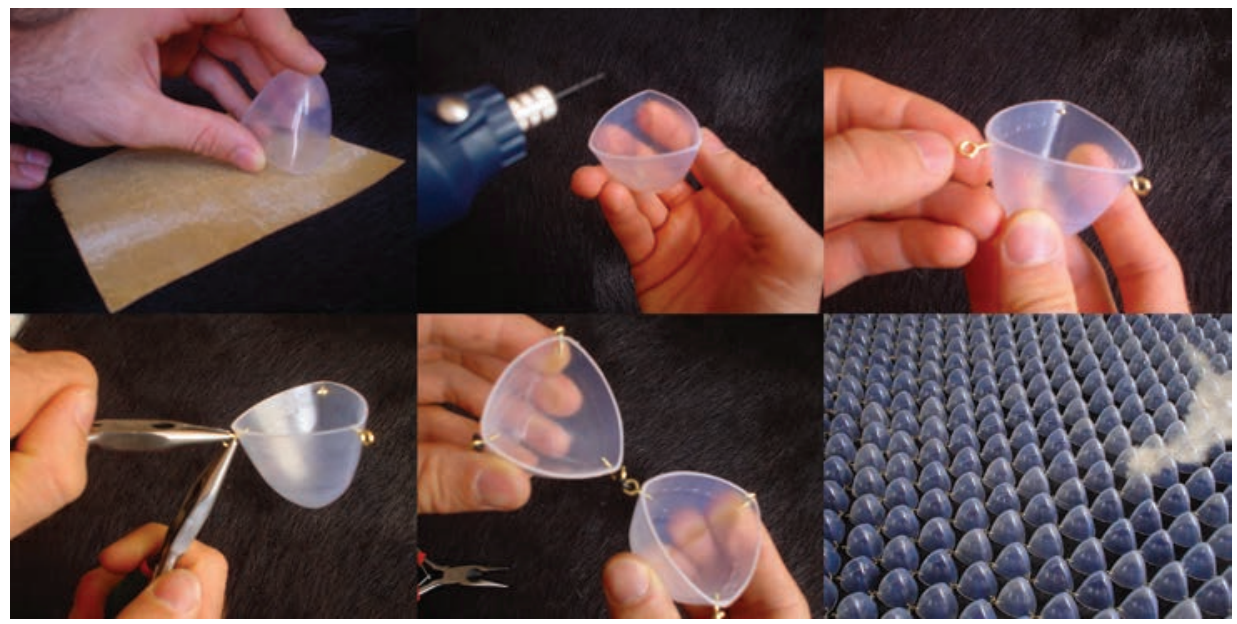

Figure 3. Making Kinetetras, Crafting (August 2002).

Photography: Vanessa Ceelen

I am sitting on a cow skin laid over the splintering timber floor of Vanessa's 100-year-old apartment in Amsterdam.

Each of the 648 half-bubbles is to be drilled at each of its three corners and at its apex.

Each corner hole has a brass eyelet turned into it.

Each corner eyelet is prised apart.

Three corner eyelets are connected together by a $5 \mathrm{~mm}$ diameter rubber 'O' ring.

The eyelets are closed.

I start ... I finish ten days later ...

$\ldots$ and I know the project.

My notebook contained sketches made in breaks in assembling the surface that directed the project to completion: the sectional configurations of the system; where they were to occur; how those configurations would shift one into the other; the different scales at which the system would be implemented; the performances in each zone; a good idea of the whole they would define, which demonstrated the kind of formal complexity sought (figure 4). 

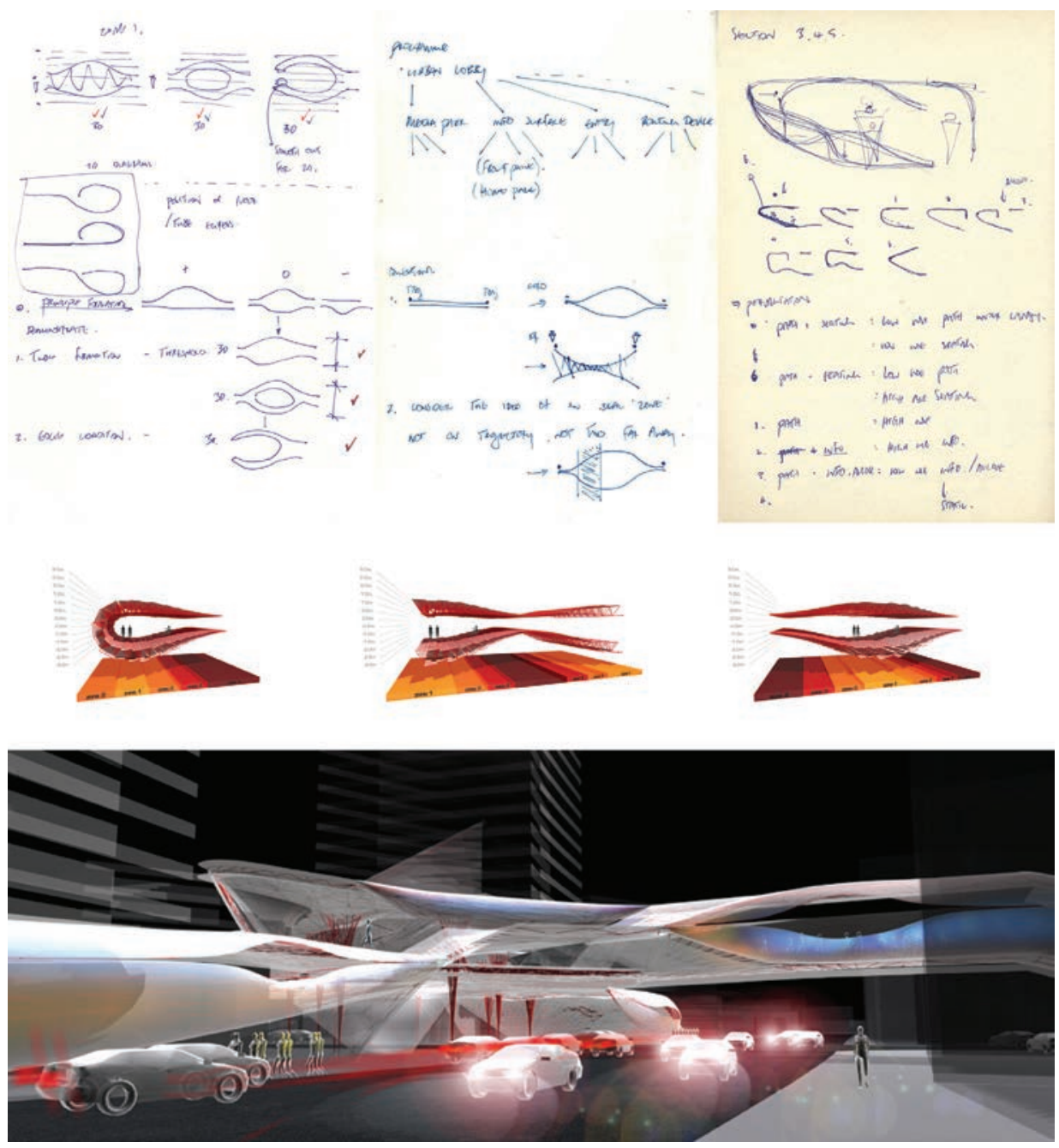

Figure 4. d_rive, (Michael Davis, Steven Hatzellis, Anat Stern), Urban Lobby at the Barbican, 2003.

Sketches and configuration renders: Michael David, Project render: Steven Hatzellis

John Dewey wrote 'New ideas come leisurely yet promptly to consciousness only when work has previously been done in forming the right doors by which they may gain entrance' (2005: 76). It seems to me that Dewey might have been describing what is commonly known as an 'AH-HA!' moment, the same kind that I experienced through making sketches in relation to the making of the Kinetetras surface. But this wasn't your everyday 'AH-HA!' moment in that it was so profound. It seemed to me that there was a direct link between the new knowledge this experience signalled, and the laborious, iterative work of assembling the surface, and the intensity of the work carried out earlier - that, through the crafting of the surface, fragments of knowledge gained from work prior were made ready, and shifted through to a higher level where they cohered. So, in the making of what I suspected might just be a formal, physical illustration 
of an idea of emergence, I found a sense (a 'sniff', perhaps) of the emergent. That 'AH-HA!' moment sits alongside the experience of vacuum-forming the plastic half-bubbles of the surface. In their making, the smell of the plastic over the hot element indicated when the plastic was ready to change state, to be sucked down over MDF molds - a sort of embodied way of knowing that something was ready to go through a change of state.

\section{The question of a notion of emergent craft}

I returned to New Zealand still with a question as to what emergence might mean to a design practice in a South Pacific context. I walked on the beach and found patterns left in the sand by the receding tide. These were familiar but my focus on them sharpened - post-AADRL I understood them as a kind of emergent condition, and my sharpened focus was evidence of having developed an attention to a sense of the emergent, and that sense is what I am pursuing through this paper as I reconsider the idea of emergence and its potential guises in relation to design: might it be that the formal complexity, which emerged from the aggregated self-similar geometries of the Kinetetras project (the implicit premise of Hensel, Menges and Weinstock), was but a visible aspect of a wider condition that emerged through the crafting of the project? What if the crafting itself was the issue rather than the formal complexity we were striving for? What other conditions might emerge through crafting?

To begin working through this question, I would like to unpack the design process for a holiday house that was built in 2012 for two of my wife's cousins and their families at Lang's Beach, an hour and a half north of Auckland, New Zealand. Subsequently I will compare this project with the AADRL Kinetetras project.

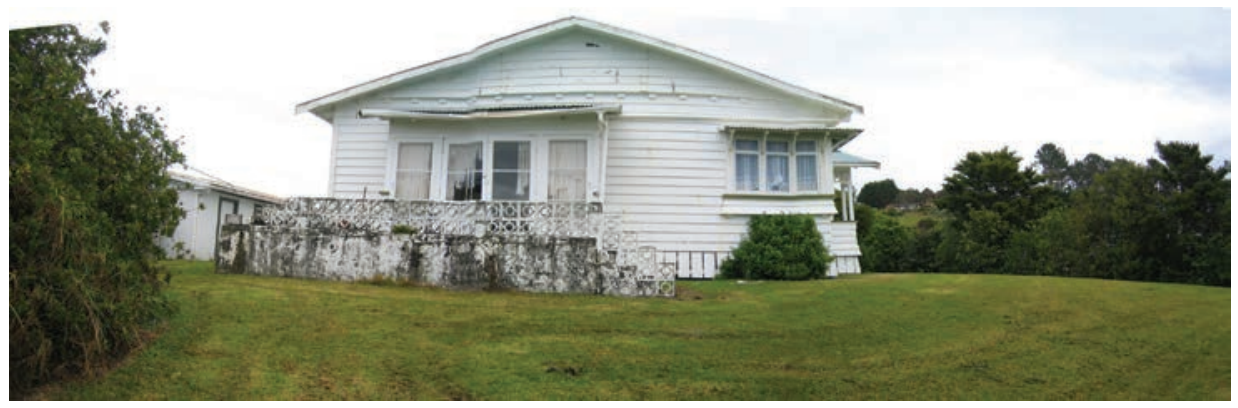

Figure 5. Existing house, 2009.

Photography: Michael Davis

The site for the house slopes northward down to the sea and has expansive views out to the Hauraki Gulf. The property has been in the family for four generations and the house that stood on the site dated from the late 1930s (Figure 5). The project outcome is essentially a large timber terrace under a timber pergola, set 
on the flat at the top of the slope, on the site of the old house. Set back from the edges of the terrace are two timber clad volumes that are tapered in plan. The larger contains the domestic functions; the smaller is a boat store (Figure 6). The everyday-ness of the project formally and programmatically makes it a useful vehicle to reconsider the idea of emergence in relation to design in a different context.

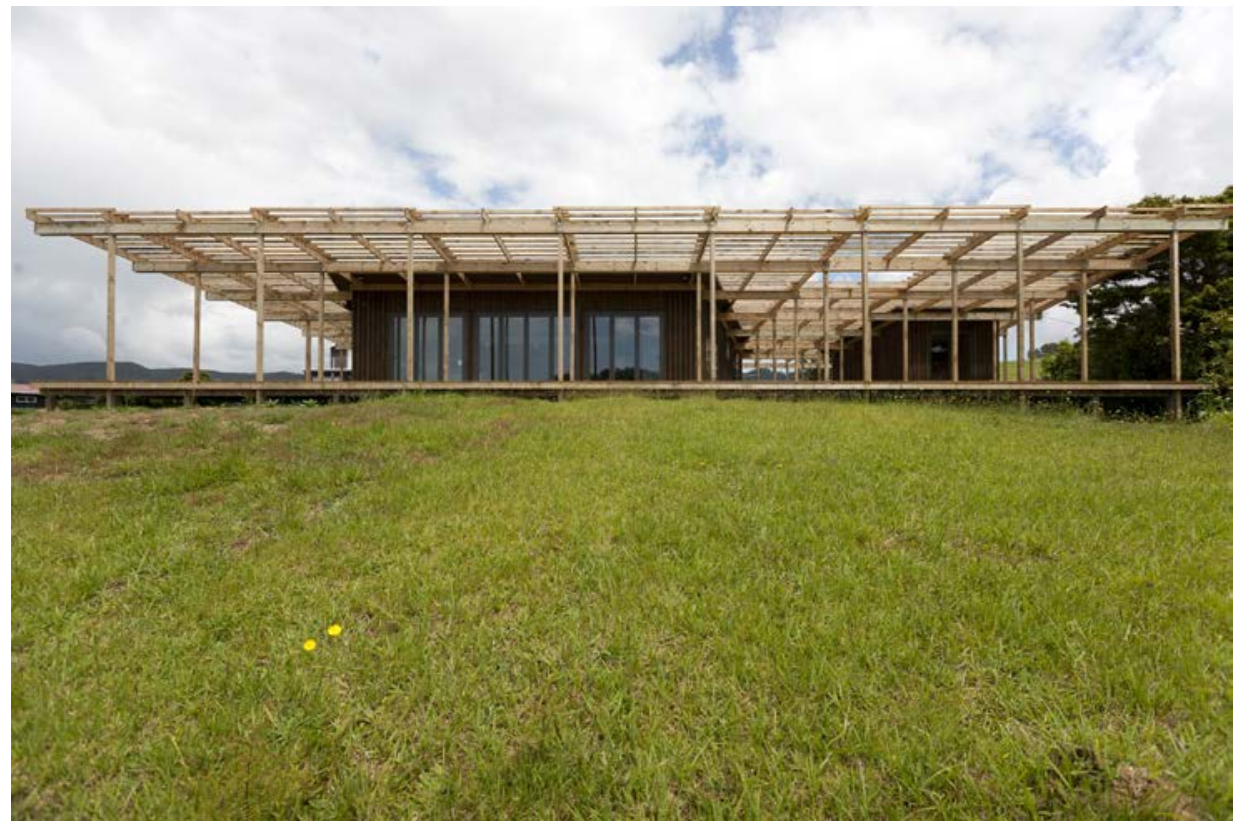

Figure 6. New house in progress, 2012.

Photography: Sajeev Ruthramoorthy

I wanted to run the project myself, but recognising a certain lack of experience on my part, I asked my father (John), an experienced developer, to partner me in the building project. We became the main contractor. In taking on that role I extended my level of responsibility from design and documentation to the management of people, timelines, finances, materials (and crucially) design opportunities, which emerged as the project unfolded. We demolished the old house.

\section{(7 January 2012)}

I have salvaged a lot of material from the old house.

We'll re-edge the old mirrors and use them in the new. Andrea cried when I told her. In my mind there it will be a beautiful memorial moment when her children look into the same mirrors as their grandparents did.

I have de-nailed and transported 600 metres of rimu match-lining and 100 metres of kauri weatherboards (Figure 7). 
Why? I don't know what I will use it for ... it feels like treasure.

My wrist has jammed up.

The builders are laughing at me.

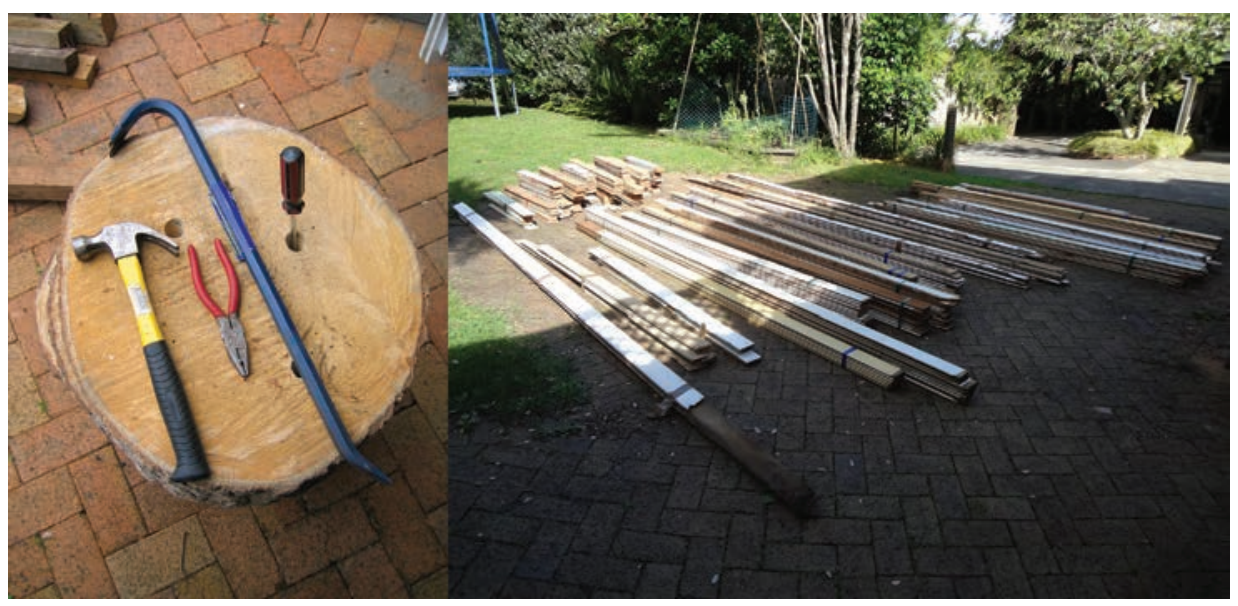

Figure 7. De-nailed rimu match-lining.

Photography: Michael Davis

(20 January 2012)

More timber is coming back.

I am spending hours at a time, bent over, under the house, in the dark, kicking cat shit out of the way, stacking salvaged finishing timber on palettes - four of them, hip high. The framing is being turned into flooring, the weatherboards will get the Mike O'Sullivan and go on the ceiling. The builders are keen but wincing at the cost to me - still shaking their heads but not laughing anymore.

I'm still carrying the front end of this project on my own. I'm running around faster in tighter circles. Where is the momentum?

I can hear the kids above. Vanessa puts on the record she brought me for Christmas.

My back hurts.

This is hard (I must be onto something).

\section{Drawing}

The designing of the Lang's Bach project was pursued initially through quick, scratchy drawings (in sketchbooks, on Post-lt notes and other loose pieces of paper), AutoCad drawings (datum plans and datum sections), Illustrator 
diagrams, Rhino models and renders. They were often made in short but intense periods of focus and appeared in sequences, with successive drawings testing the impact of changing variables in the material systems in play. Each medium was acted within quickly and from each something was taken to move the project on that little bit further. It was a drawing practice which operated across the top of a number of media, rather than through the depths of any one medium.

(2 January 2011)

Make a set of sketch configurations in plan.

Choose one or two or ... eight to test/develop more precisely in a digital drawing.

Load them up with all sorts of constraints and possibilities.

On this basis develop other options. Others will not be tested ... as I work I get a stronger sense of which are worth trying. Tracing over the options by hand helps to make decisions as to what to proceed with.

Look at them all again and ask what the project is about. And then strip it all out again - to reduce the conditions present to those that are core to the project. I know what is core because in the process of loading it up I develop a sense of what works and what doesn't.

I am conscious of a feeling of exhaustion. I am locked in. I close my eyes and I still see the drawing. It is like having played a video game for too long.

\section{Knowing-through-drawing}

Downton picks up Schöns' 'knowing-in-action' (1983). In unfolding a notion of 'knowing-through-making', Downton discusses '... the interaction between the ongoing making of a representation and the evolving knowing of the designer making the (probably partial) representation' (2003: 101). What he opens up, but does not pursue, is the idea that different types of making might yield differing types of knowing: Knowing-through-making-a-model might be different to knowing-through-making-a-drawing.

(4 April 2011)

Andrew Barrie stands at the open door of my office. He points at the version two model.

'It's not quite there', I say.

'Why?'

'Because the plan figure lacks clarity - it is like boxes of space wrapped in Gladwrap.' 
'But you'll never experience the building as a plan form.'

'I know, but it doesn't change the way I feel about it.'

My 'knowing-through-drawing' had me resisting the irregularity of a particular plan figure. The geometry wanted to be simple. It wanted to conform to a ninesquare grid, but couldn't do so, despite a protracted struggle. In the struggle it had become bound within itself and in relation to the grid of the pergola above - it made me wince. When I drew a diagonal line across the grid of the pergola I got a flash of a sense of freedom - a sort of small 'ah-ah' moment - which I eventually pursued into version three of the project.

What does knowing-through-drawing mean below the level of the complete geometry, at the level of the individual lines which are aggregating? I would like to propose a model of my drawing practice with the benefit of the reflection upon Lang's project and the work of Schön and Downton: I always have a geometric idea before I draw, but it is a germ of an idea - a line, shape or form perhaps, never a fully formed image of a building. Each line, as it is being drawn and once drawn, is immediately/simultaneously evaluated in terms of both the emotional response I have to it relative to its location, shape, quality, and its subsequent relationship to the initial idea. Is the line good, adequate or bad in terms of the geometric entity that I am attempting to represent? When I draw a line that I don't like there is a wrestle - is it just that line or the whole idea that is the problem? More often than not I push this micro-discomfort aside in the understanding that it is just that line.

The word 'understanding' is important as it implies a shift in the level of consciousness at which these micro-scaled evaluations are taking place - a micro-emergence. For the most part, this evaluation process occurs immediately, in 'real time'. The slowing, the interruption of the rhythm, the discomfort established in the drawing/evaluation process brought about by the 'wrestle' may bring that issue, momentarily, more fully into consciousness.

As I continue to draw, and the idea changes and develops, so too do the evaluation criteria.

As I draw further a more fully formed idea emerges and the lines are evaluated against the growing sense of the whole. At the micro-scale being discussed, there is an immediacy between the geometric idea, its drawing, and its evaluation that feeds back into the idea, the geometry, the evaluation and so on.

So, just as the lines aggregate to define the representation of the whole ...

So, too, do the micro-evaluations aggregate to form a judgement of the whole ...

And so, too, do the feedback loops aggregate to form a 'knowing' of the emerging whole.

Knowing-through-drawing is an emergent form of knowing which works on the fringes of consciousness. 
craft + design enquiry

\section{Crafting models}

The physical model was the firm, physical statement of intent that the drawings fed toward. Over 12 months, the project ran through three full cycles of scratchy drawing through to a 'finished' (rather than 'final') 1:100 scale physical model.

(17 April 2011 in relation to the completed version two model)

I am noticing the physical symptoms of the strain of making this model. The base of my skull is itchy, my eyes are flicking. It seems I live in a constant state of stress, only the level varies. I only realise this through the moments of relaxation and fun I encounter in the work.

When I make a model of the kind I have just finished I am nagging at myself 'it's taking too long!' - eight days here. But when I make a fast model I lack a sense of certainty, the kind that comes on the basis of a quantity of work. I might project a solution. But if it's not perfect at the outset (and it can't be) an internal commentary of 'that's not it'; 'that's too heavy'; 'how are you going to clad that?'; 'it's over budget ... to expensive ... too indulgent ...', begins. This is judgment, un-bridled self-criticality, self-editing. It is crippling.

Relative to the making of the drawings, modelling was a materially invested, detail-focused, more concerted mode of making and, somehow, more personally introspective ... and it was much slower. As indicated in the notation above, this slower mode of production saw a level of debilitating self-criticality surface.

\section{Finished models}

Escaping that self-criticality becomes a central theme to my practice. That escape might require a sense of humour coupled with a sense of possibility (rather than predetermination) in the work. These qualities present most clearly in the version one model in the scales and materials applied to represent the various elements and in their juxtapositions: the over-scaled red flax relative to the lime green foam relative to the faux, super-green grass; the bamboo skewer trees relative to the blue, kitchen sponge hedges; and, if you look closely enough, the tourist-with-camera and the woman-in-kimono who occupy the model (Figure 8). With this juxtaposition of elements, the version one model works in a very similar manner to a Photoshop collage, simultaneously projecting precision and yet a quality of the provisional: speculation and fun. In doing so, the 'finished' model retains a sense of openness to change. 


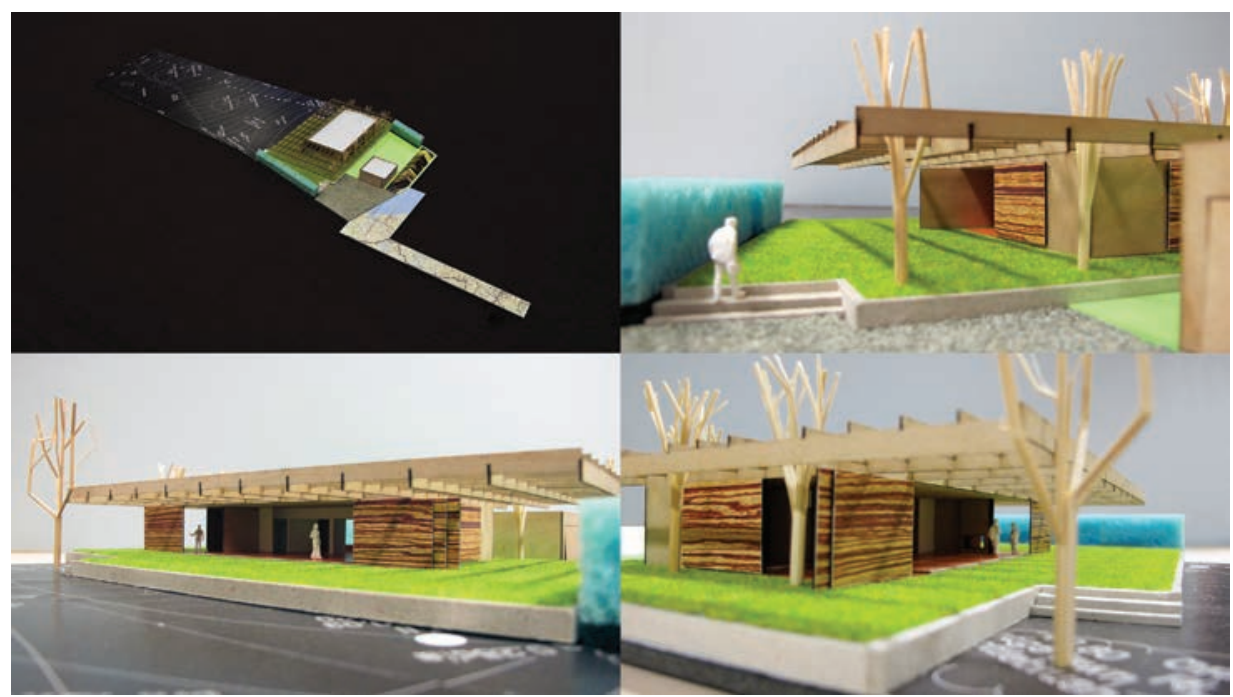

Figure 8. Version one model.

Photography: Sajeev Ruthramoorthy

\section{Paper models}

The two paper models at 1:200 scale were made after the presentation of the version one model (Figure 9). Perhaps due to a perceived lack of speculative drawings (relative to previous projects) prior to the making of the version one model, I felt the need to test the direction of the project against another viable direction through physical modelling. And I needed to avoid the mode employed in the version one model - it needed to be faster, less detailed and more materially ambiguous. This was an exploration that took me away from the tedious preparation of AutoCad files for the laser cutter, and into a new combination of physical modelling using Illustrator. The significance of the paper models in terms of the research is that, in their making - with the new technical challenges they presented, and with the speed of production they facilitated - the self-criticality abated.

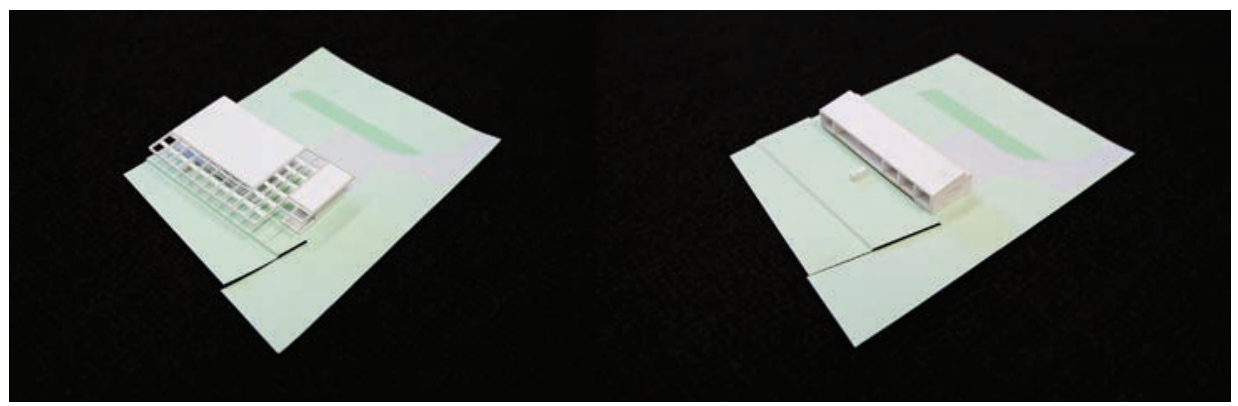

Figure 9. Paper models.

Photography: Sajeev Ruthramoorthy 


\section{Knowing-through-modelling}

Modelling is a particular kind of making and a particular kind of knowingthrough-making might be expected to emerge. Modelling concerns cutting, folding or otherwise manipulating material, and the subsequent assembly of pieces. Cutting card, for instance, involves the holding in my left hand of a retractable, snap-off blade knife at a particular angle, with a particular pressure; holding with my right hand a metal ruler with a non-slip rubber strip on the back - my thumb and first two fingers pressing down along its length. My right wrist, elbow and upper arm define a ' $Z$ ' shape, my right shoulder is down; my left elbow is shoulder is high and shrugged, my arm relatively straight, my forearm tense through holding the knife. The twist in my body starts at the tip of the knife, runs through my arms, is exaggerated through my shoulders runs down my back into my hips. My right hip is drawn forward, my weight bears over my slightly bent right knee. The ball of my left foot balances me, my left heel is raised. My position changes, the twist is exaggerated as I bend my arm, as I pull the knife toward me through the card. One cut is made. The number of cuts made in this embodied manner in the production of a single model may well be comparable with the number of lines drawn across that part of the design process which defines the model to be made.

(April 2011)

Resonance is a feeling. When I am modelling in a faster manner resonant conditions present more quickly, not quite in an instant, but in ways and at speeds which tend to surprise. They produce mild excitement - I smile, I get itchy in my hamstrings, I have to move around, I sit back, I stretch. I get keen. I work for these moments.

When I am making in a more focused, singular, slower manner, perhaps focused on resolving a single issue, resonance presents itself as an absence of the agitation that builds in me when I work this way. This is a calmness. It dawns. It is relief. I get it when the pieces I am concerned with are set in relation to each other in a way that is good, pleasing, consistent with each other and/or the whole.

Just as the lines aggregate, are evaluated, and micro feedback loops established, so too are the cutting actions of the modelling craft. The difference is that the role of my body, the material and the tools are perhaps more pronounced in the actions of making a cut relative to drawing a line. The opposite might be said of my level of conscious thought. The 'wrestle' described earlier in relation to drawing a line is less likely to occur in making a cut as it is following a line that has already been drawn. The result is that knowing-through-modelling occurs more in my body - I catch myself smiling and have to ask 'Why? What just happened?' It seems that, as my bodily activity increases and the worry diminishes, conditions become more primed for emergent realisation. This emergent, embodied knowing might also be termed 'sensitivities'. 
Beginning with the drawing of lines, and the clicks of a mouse, with the cutting of card, I make.

Through the making I develop sensitivities to the project.

This extends my knowledge of the project at larger and smaller scales. My capacity to contribute to the project through my making across these scales is thus extended.

... with the drawing of lines, ... (this is self-perpetuating)

In the making of a drawing or model I engage with the project beyond simply representing a building. In the case of the version three model for the Lang's project this involved, for instance, not merely drawing and assembling a timber pergola post at 1:100, but through drawing and assembling the post, I developed a sense of what the material was, the machining of the timber, the excavation required to accommodate it, where the spoil would be located, the time and labour involved, its structural performance and the load it would endure in the wind, and its effect upon the space it would define and upon the occupants that would inhabit that space.

This investment in the project through my craft practices reached through the finished models into the world to yield a base of knowledge about the project upon which decisions as to what was good, bad or indifferent were made. Crucially this sense was not dependent upon the actual experience of machining or founding a timber pergola post. But it was dependent upon my willingness to engage with the material world across scales and differing environments through making drawings and models. The resulting emergent sense of empathy with the labour and material consequences of the design was subtle but persistent.

\section{A productive tension}

What the preceding accounts provide is evidence of emergent conditions and knowledge in the design process: 'Knowing-through-making' (Downton 2003) is an emergent condition - a macro-aggregate of micro-actions, microevaluations and micro-feedback loops established in the making of a designer. This aligns 'knowing-through-making' with Johnson's notion of emergence. Following on, two issues are becoming clear: the first is that knowing-throughdrawing and knowing-through-crafting models are complementary ways of knowing-through-making. They differ in terms of the tools and materials and the level of bodily engagement involved in each; the second is that they operate in tension. It seems that central to the development of the project are two objectives related to this tension: Escaping the self-criticality that comes with slow craft; and maintaining a sense of speculation and openness in the project as it develops. Micro-responses to this tension, whether they present in my body (in a smile or a wince, for instance), or whether they be in my material decisions (foamboard over timber, for example), also aggregate to yield an emergent quality of approach to design-craftiness. 
craft + design enquiry

The site model

(8 April 2011)

Problem: The Lang's Site Model. I am sketching in my book, trying to think of a way to make it. It must be light, easy, fun, (most importantly) something I have not done before.

Solution: Black foam board profiles. Top side covered in black fabric and varnished (Figure 10).

Excellent! The site model (the most mundane element perhaps) has me excited about the project again. The task of making a FINAL model the demand for the perfect, predetermined, fully resolved patterns that the laser cutter demands - is excruciating. This site model task is new and the quality of the outcome is not predetermined - it is a material experiment.
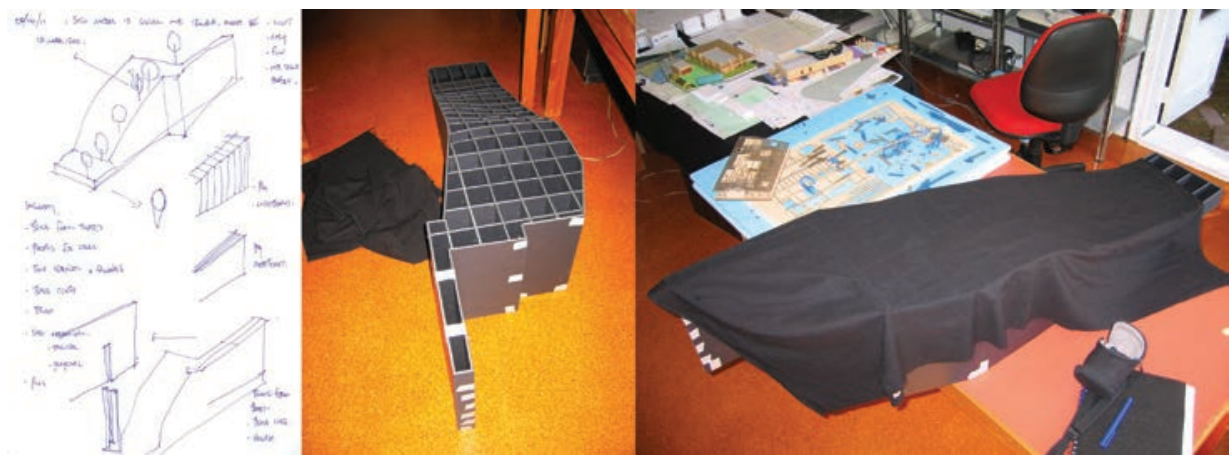

Figure 10. Site model in the making.

Photography: Michael Davis

(13 April 2011)

The slot together structure of the base is related to how the rafters slot over the beams in the version one model. I am nearing the end of the work for the day - it's midnight. I am hesitating. How do I treat the edges of the cloth so that it covers the top edge of the site frame? How to treat the ragged edges? All this hesitation in spite of already having decided how to do it - by pinning the edge provisionally, cutting it to leave an even surplus, folding the edge back onto double sided tape and pinning through into the edge of the foam-board frame.

This is not craft. If it was I would not be using foam board but timber, it would take eight days to make and I would drive myself insane. My desire to make well is extended by a desire to develop new ways of doing (ordinary) things. It is tempered by a concern that the entity I am to make contributes to the wider design process it is a part of rather than becoming the focus - it is an end but more importantly it is a means. Holding it in this role is a tactical issue, in this case actioned by material selection the cloth over the foam board rather than timber.

This temperance perhaps also allows the model to open up new ways of thinking. 
Craftiness is a craft-informed, collage quality of approach to design: through it I escape the crippling self-criticality that comes with slow craft either by employing faster modelling techniques, or by introducing new modelling techniques that draw focus away from the slowness. It also brings a quality of openness and speculation by projecting provisional relationships through the juxtaposition of techniques (in the process) and components (in the outcome). The relationship between the escape, speculation, and the collage-quality here is circular and tightly bound. While their hierarchy, therefore, is not entirely clear, I suspect that the desire to escape self-criticality lies at the core. The effect of craftiness in juxtaposing the differing material components in the models is to resolve an apparent paradox, where the models (as described earlier) simultaneously project a quality of precision, and yet a quality of the provisional and speculation.

\section{Tracking craftiness}

Might craftiness be tracked into the architectural outcome?

The brief presented an ambition for a four bedroom, two bathroom house with a large shared living space - one that would comfortably accommodate the two sisters and their growing families simultaneously. The budgetary means were smaller by comparison. The compromise was to ally an entry with a combined kids' sleeping, AV area and playroom to the rear, and to run this parallel to a larger scale living, dining, kitchen space on the seaward side of the building. The result is a problematic programmatic/spatial adjacency which warranted sharp focus in the design process.

(7 April 2011)

I packed up the Lang's work and relocated it to UoA.

I ran across the first 'quilt' drawing (Figure 11).

It shows a concern for occupying the site in multiple ways.

Even if, or perhaps because these are shown somehow compartmentalised, the interesting bits are the lines, the interfaces between these pockets of program/space.

What is the nature of each spatial division? 


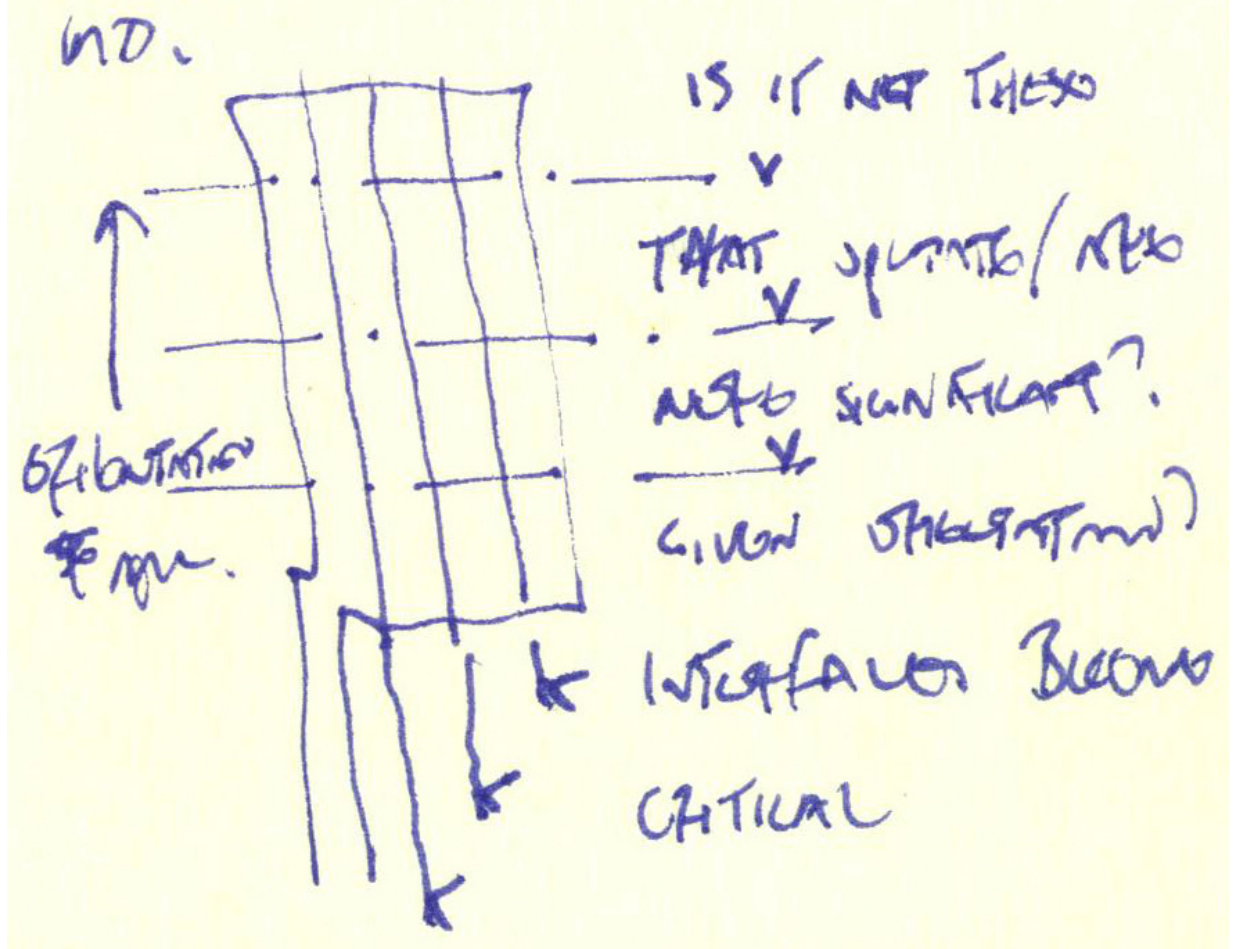

Figure 11. Quilt drawing.

Sketch: Michael Davis

Delineation between the zones is established by a 140-millimetre $(\mathrm{mm})$ step up into the kids' zone. The timber doors are each 2.1 metres high by one metre wide. They run along the edge of the step, which is paralleled by a bulkhead above that holds the track from which the doors are hung. Perpendicular to the doors is a cabinet that separates the entry space from the remainder of the kids' zone. It slides apart to lengthen the entry space, focusing movement through the entry into the adult living space and simultaneously closing the corner of the children's zone to reveal the AV gear within. The cabinet corresponds to the height of the doors but is open above. It slides along the floor to butt into the face of the first door, just creeping under the bulkhead to do so (Figure 12). 


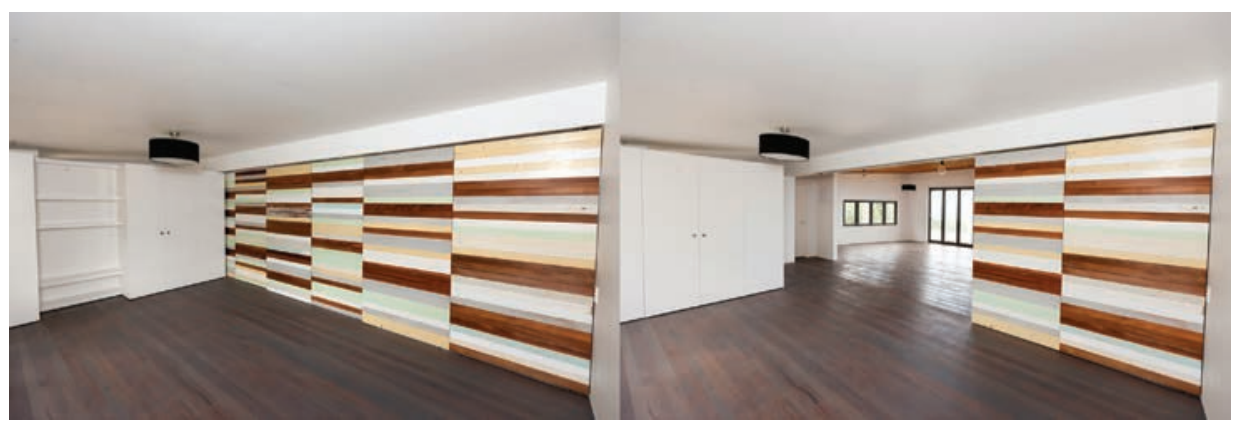

Figure 12. White cabinet versus recycled rimu match-lining to doors.

Photography: Sajeev Ruthramoorthy

The cabinet took on the same white of the plasterboard-lined walls, but in a low gloss lacquer rather than a matt. To the children's zone, this was juxtaposed with the recycled rimu timber flooring and the existing paint colours of the recycled rimu match-lining to the sliding doors - stripes of peppermint green, French Vanilla cream, matt grey, muted turquoise blue, and flaking white. The sense of provisionality and fun that emerges from these juxtaposed elements pervades the space - it is its defining quality. It bears a strong resemblance to the 'Photoshop collage' sensibility of the finished models and the version one model in particular. It is a point where craftiness bursts through into the final outcome - it changes state from being a quality of approach to being a quality of outcome.

\section{Tracking craftiness further}

The sliding door system had persisted and had been adapted through shifts in the project informed by client preference, encounters with technical constraints, and the gradual revelation of the availability and type of timber salvaged from the old house. My commitment to the door system from the outset is illustrated in the version one model through their highlighting in the zebrano timber pattern. What began in that model as two sets of two 2.4-metre-high by 3.6-metre-wide exterior, wide-slat timber shutters became, in the built outcome, six 2.1-metrehigh by one-metre-wide interior hollow-core doors, faced in $12 \mathrm{~mm}$ recycled rimu match-lining to both sides, and with a CNC relief milled into one of those (Figure 13). 


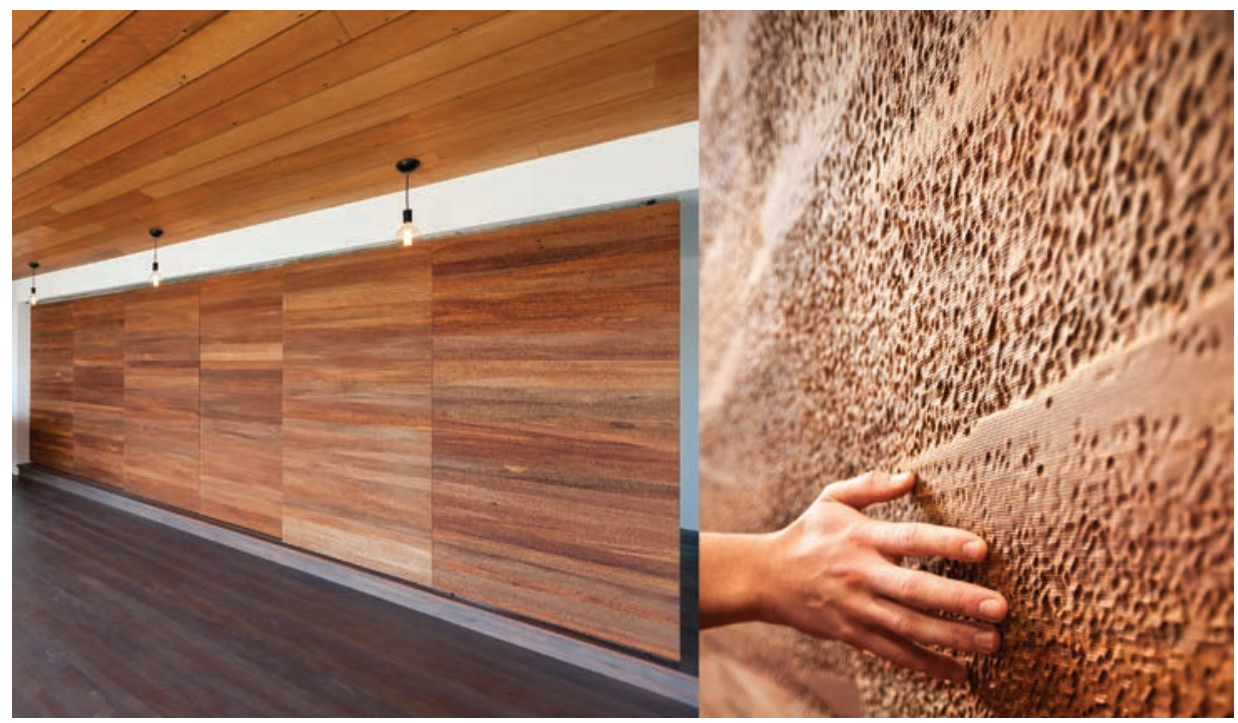

Figure 13. CNC relief to recycled rimu match-lining to doors.

Photography: Sajeev Ruthramoorthy

To explain what this has to do with emergence: earlier in this text I outlined a quandary I had about the discussion of emergence in architecture that I was engaged with at the AADRL, and what it might mean in the everyday-ness of practice in New Zealand. I recounted a moment walking on the beach, seeing patterns left in the sand by the receding tide, and understanding them (postAADRL) as an emergent condition. What I developed at the AADRL was an attention to a sense of the emergent.

One particular photograph of one particular sand pattern informed the CNC relief to the doors. In setting the relief within the larger project, what was achieved was a juxtaposition of an image-of-emergence with an (actually) emergent behavioural condition (craftiness), emergent relationships (between components), and emergent qualities of outcome evidenced in the project. That juxtaposition was the seed for this paper.

The 600 lineal metres of rimu match-lining that I extracted from the old house and de-nailed was machined down so as to line both outer faces of a hollowcore door leaf. Consideration of the direction of the flooring and the ceiling (which articulate the 'grain' of the space) informed the horizontal direction of the rimu strips to the doors. My friend and research assistant Sajeev Ruthramoorthy and I took 120 photos of sand patterns. I reviewed the photos, reducing the file count to ten. Sajeev developed a 3DSMax template file into which the ten images were dropped. Each was scaled and a displacement map was generated on the basis of the relative light-dark ratio to produce a digital model. We reviewed the outcome, looking for the most compelling - that which would produce the 
clearest, most consistent model relative to the sand pattern. Five were selected. Depth and blur variables were manipulated, and renders made in elevation and perspective to determine settings for the final models (Figure 14).
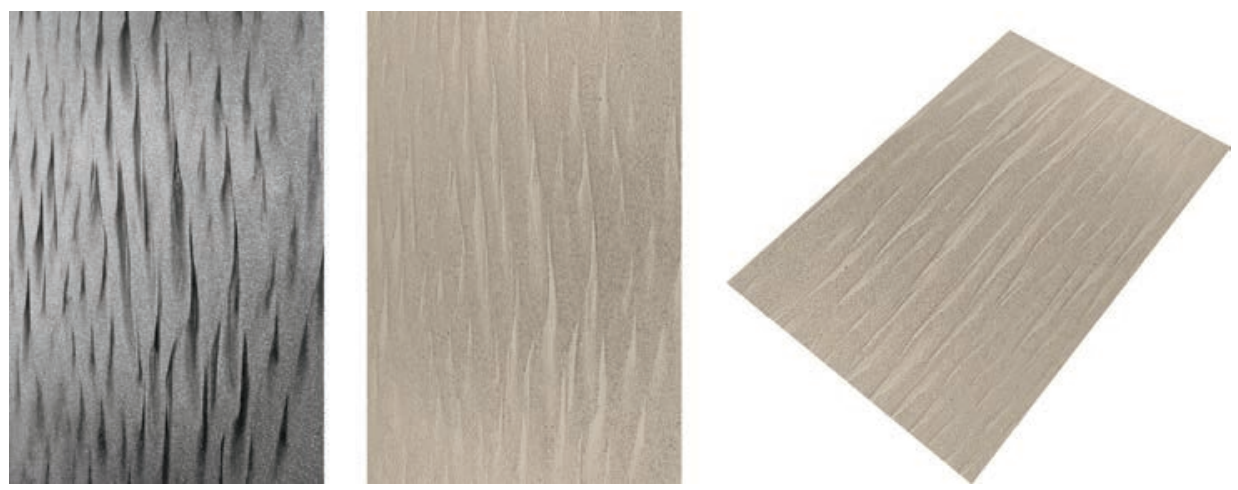

Figure 14. Sand pattern \& 3DSMax test renders.

Photography: Sajeev Ruthramoorthy

We tested a $450 \mathrm{~mm}$ square portion from one file in foam. The six $\mathrm{mm}$ bit with a two $\mathrm{mm}$ step over produced a surface that was too coarse and, at the same time, not detailed enough - the six $\mathrm{mm}$ bit would not go into the depths the file projected, as the tip of the bit was too wide. So, while we had a nine mm depth available to us, the cut depth was limited to around four $\mathrm{mm}$. Next we ran a six $\mathrm{mm}$ rough cut with a two $\mathrm{mm}$ step over, followed by a two $\mathrm{mm}$ fine cut with a 0.5 $\mathrm{mm}$ step over. With a feeling for the settings developed from the foam tests, we ran a test in the timber. From the tests we were able to go back into the 3DSMax model, and further back into the Photoshop file to fine tune ... and this process continued into the production of the doors.

There is an immediacy afforded by the narrow gap between the representation and production technologies. That immediacy facilitates a feedback loop in the reciprocal relationship between the image, the model and the 1:1 prototype at a detailed level. The speed of operation between these technologies, and the superficial use of each to progress the project, is a similar ethos to the drawing practice outlined earlier in this text - it is a crafty collaging of techniques in the production and detail to achieve a sense of openness and speculation at this level.

Craftiness is an emergent collage quality of approach to design that issues from the tension between two forms of knowing-through-making: drawing and modelling. Compositionally craftiness holds the Lang's Beach house project together across the process of designing it through into the detail of the outcome - from the quilt drawing into the production of the doors. Craftiness emerges as the key quality in the project.

The craft of the architect is concerned with the making of representations of an artefact to be made by others. But it is through the making of those 
representations that the attentive practitioner may also develop a feeling for the implications of the artefact being represented at smaller and larger scales from detail to context, from the front doorstep to the city.

What the Lang's project (also) shows is that the qualities we strive to draw forward through crafting a drawing or model have the potential to find their way into built outcomes and to distinguish them experientially. Our craft practices matter to the world to which we contribute.

\section{Juxtaposing projects}

The AADRL Kinetetras project and the house at Lang's Beach are half a world and ten years apart, but they each provide a perspective as to how the other might be understood. What I experienced at the AADRL in making the Kinetetras prototype was a 'sniff' of emergence. But it is evident that emergent conditions also presented across the Lang's Beach project.

The type of craft processes involved in making the surface for the Kinetetras project were vastly expanded across multiple dimensions in the Lang's Beach house project. They worked not only into and through my body in the making of models, but into the de-nailing of the timber recovered from the old house, into the making of the doors, and into running the contract; they ran through the varying types of reflection captured and presented here; and they ran into my family as both co-contractor and client - I was deeply involved in many ways. The AADRL was intense, but it was not as intense nor as protracted as Lang's Beach. While Kinetetras was a small part of a system consisting of a few component types and relationships repeated extensively, Lang's Beach was a whole building consisting of multiple types of components and processes and relationships played out with limited repetition in relation to specific circumstances (around a programmatic adjacency in the case of the doors, for instance). While it did not pursue the language of formal complexity, which the Kinetetras project did overtly (even prescriptively), it was vastly more complex relationally.

In terms of a sense of the emergent, the phase shift that Kinetetras went through was singular and pronounced - one big 'AH-HA!' moment - perhaps due to the extensive repetition of the very limited types of components and relationships involved. With Lang's Beach, that phase shift was substantially more protracted and was much less pronounced. It consisted of much smaller ('ah-ha') moments, such as the diagonal line in relation to the pergola grid, or the decision as to how to make the site model. Each signalled one of a raft of relationships coming into being and, yet, each had to be held provisionally as others came into being (as each new relationship may have effected further shifts in existing relationships) and were drawn into the emerging whole. To provide an analogy: it was similar to the formation of carbon-based polymers - link to link; chain to chain ... 
slowly, gradually they fit together, the relationships become firmer, and the mix becomes more viscous as the polymer (design) emerges. Each little 'ah-ha' moment was a point where some sort of relationship congealed.

The Lang's Beach doors might be understood as a project that parallels Kinetetras, but one that offers a critique of the formal agenda pursued in the name of emergence to which Kinetetras contributed. The geometry for the doors was extracted from patterns in the sand - an everyday occurrence for me - and imprinted into a material to provide a surface effect. On their own, they were illustrative of an idea of emergence, just as Kinetetras was, but in the context of the project, that meaning was subsumed in the emergent raft of relationships that presented in its making. What the doors do in the building is punctuate the complexity of that raft of relationships.

My research into emergent complexity in design began at the AADRL with the Kinetetras project. The Lang's Beach house re-grounds that research in an everyday context, and the pursuit of a sense of the emergent through embodied craft practices, I now see, is an everyday aspect of design.

Mike Davis is a Senior Lecturer at the University of Auckland, School of Architecture and Planning, and a practicing architect. He received a Master of Architecture from the Architectural Association, London in 2003 and is currently involved in Doctoral research at RMIT, Melbourne.

\section{References}

Dewey, J. 2005, Art as Experience, New York: Perigee / Penguin Group.

Downton, P. 2003, Design Research, Melbourne: RMIT Publishing.

Johnson, S. 2002, Emergence: The connected lives of ants, brains, cities and software, London: Peguin.

Metcalf, B. 2002, 'Contemporary craft: A brief overview', in J. Johnson (ed.), Exploring Contemporary Craft: History, theory \& critical writing, Toronto: Coach House Books and Harbourfront Center.

Oxford, 2012, Oxford Dictionaries, viewed 27 April 2012, http://oxforddictionaries. com/definition/craft? $q=$ craft

Schön, D.A. 1983, The Reflective Practitioner: How professionals think in action, New York: Basic Books.

Sennett, R. 2008, The Craftsman, New Haven, Conn.: Yale University Press. 